\title{
PENGARUH WARNA SUNGKUP SEBAGAI PENYARING CAHAYA TAMPAK TERHADAP PERTUMBUHAN BIBIT ANGGREK DENDROBIUM PADA TEKNIK SEMI HIDROPONIK
}

\section{EFFECT OF COVER COLOUR AS VISIBLE LIGHT TO GROWING DENDROBIUM ORCHID SEEDLING IN SEMI HIDROPONIC TECHNIQUE}

\author{
Tini Sudartini ${ }^{1}$, Rifa'atul Maulidah ${ }^{2}$ \\ ${ }^{1}$ Program Studi Agroteknologi Fakultas Pertanian Universitas Siliwangi \\ ${ }^{2}$ Program Studi Pendidikan Fisika Fakutas Keguruan dan Ilmu Pendidikan Universitas Siliwangi, J1 \\ Siliwangi no 24, Kec. Tawang, Kota Tasikmalaya, Jawa Barat Indonesia
}

Korespondensi : tinisudartini@yahoo.com

\begin{abstract}
ABSTRAK
Anggrek memiliki arti penting dalam perdagangan bunga dan menjadi komoditi tanaman hias dengan nilai jual tinggi serta harga yang relatif stabil setiap waktu. Anggrek Dendrobium merupakan salah satu jenis anggrek yang menempati posisi teratas dalam urutan trend pasar anggrek. Dengan minat yang besar terhadap komoditas ini, maka dibutuhkan perbaikan teknologi budidaya seperti penggunaan sungkup plastik tanaman. Tujuan penelitian ini ialah untuk mengetahui pengaruh berbagai warna sungkup sebagai penyaring/filter cahaya tampak terhadap pertumbuhan bibit anggrek Dendrobium pada teknik semi hidroponik dan menentukan warna sungkup plastik yang paling sesuai untuk pertumbuhan terbaik bibit anggrek Dendrobium pada teknik semi hidroponik. Penelitian ini menggunakan metode eksperimental. Rancangan percobaan yang dipergunakan ialah Rancangan Acak Kelompok (RAK). Faktor perlakuan yang dicoba adalah berbagai warna kantong plastik sebagai sungkup pembibitan anggrek yang terdiri dari 8 warna yang digunakan untuk sungkup (warna sungkup), terdiri dari perlakuan A: Pembanding/ Tanpa sungkup ; B: Warna sungkup merah ; C: Warna sungkup jingga; D: Warna sungkup Kuning ; E: Warna sungkup Hijau; F: Warna sungkup Biru ; G: Warna sungkup Putih/Bening ; H : Warna sungkup Ungu . Percobaan diulang 4 kali. Satu perlakuan terdiri dari 5 bibit, sehingga terdapat 160 bibit. Hasil penelitian menunjukkan warna sungkup berpengaruh terhadap jumlah daun umur 30 hst. Jumlah daun lebih banyak $(5,42$ helai) terdapat pada sungkup yang berwarna kuning dan putih.
\end{abstract}

Kata kunci : Bibit dendrobium, warna sungkup, cahaya tampak, semi hidroponik

\begin{abstract}
Orchid have high economic value in ornamental plant trade with relatively stable price. Dendrobium is orchid type that have high position in trade market. Demand of this orchid type is being increase year by year. It needs improvement of cultivation technology including the use of plastic cover into the plant. The purpose of the research is to study the effect of plant cover colour as a visible light filter to dendrobium growth on semi hidroponic technique and to determine the prover cover colour for growing dendrobium seedling. The research uses an experimental method arranged with Completely Randomized Block Design. The treatments is the covering the plant by various plastic cover colour, that are : A. Control/without covering; B. Red plastic cover ; C. Orange plastic cover; D. Yellow plastic cover ; E. Green plastik cover ; F. Blue plastic cover; G. White/Transparan plastic cover and H. Purple plastic cover. The treatment is replicated by 4 times with 5 seedlings per treatment, in total 160 seedlings for
\end{abstract}


whole tratments. The result shows that the colour of plant plastic cover effected the number of leaves 30 days after planting. The white/transparant plastic cover gave more number of leaves produced (5,42 laminated) compared to other colours used.

Key words: Dendrobium seedling, plant cover colour,visible light, semi hidroponic

\section{PENDAHULUAN}

Anggrek merupakanan tanaman hias yang bernilai estetika tinggi dan memiliki arti penting dalam perdagangan bunga. Selain karena bunganya yang indah dengan warna yang menarik anggrek dapat dijadikan sebagai tanaman pot maupun bunga potong. Anggrek sudah menjadi komoditi tanaman hias yang memiliki nilai jual tinggi dan harga yang relatif stabil setiap tahunnya (Abdul Muhit ,2010). Luas panen yang meningkat mencerminkan permintaan terhadap anggrek meningkat. Dengan minat yang besar terhadap komoditas ini, maka dibutuhkan teknologi budidaya yang tepat dan efisien sehingga pemenuhan permintaan dapat selalu terpenuhi (Boga, Williem, Tumbuan, 2015).

Dalam usaha budidaya tanaman anggrek, faktor lingkungan seringkali kurang ideal. Kelembaban udara dan suhu di lokasi penanaman anggrek yang kurang optimal yang menyebabkan pertumbuhan tidak maksimal. Menurut Yusnita (2010), suhu ideal untuk pertumbuhan dan pembungaan anggrek Dendrobium yaitu pada kisaran suhu minimal $21^{\circ} \mathrm{C}$ sampai $23^{\circ}$ $\mathrm{C}$ dan suhu maksimal $31^{\circ} \mathrm{C}$ sampai $34^{\circ} \mathrm{C}$, dengan kelembaban udara berkisar $60 \%$ sampai $80 \%$. Faktor kelembaban udara mikro sekitar pertanaman perlu diperhatikan apalagi pada tahap aklimatisasi dan pembesaran bibit yang berasal dari kultur jaringan. I Gede Ketut Adiputra (2009), menyatakan, tanaman hasil kultur invitro memiliki lapisan lilin (kutikula) dan jaringan pengangkut belum belum berkembang sempurna, akar belum bisa berfungsi dengan baik, stomata sering sekali tidak berfungsi tidak menutup ketika penguapan, keadaan ini menyebabkan pucuk-pucuk bibit anggrek sangat peka terhadap transpirasi, serangan cendawan dan bakteri.

Salah satu upaya untuk mengatasi hal tersebut ialah dengan cara menumbuhkan bibit di lingkungan dengan kelembaban yang tinggi. Satu teknis yang sederhana yang mudah dan murah yaitu dengan cara menumbuhkan bibit secara individu di cup plastik yang dapat menampung cairan setinggi $1 \mathrm{~cm}$ dari dasar wadah tanam. Sedangkan untuk membantu mengendalikan transpirasi dari daun bibit muda bisa diatasi dengan penyungkupan memakai kantong plastik high density polyethylene ( hdpe). Kantong plastik hdpe yang sifatnya transparan apabila digunakan untuk sungkup masih bisa meneruskan cahaya matahari sampai ke permukaan tanaman. Menurut Leyla Bayat, Mostafa Arab, Sasan Aliniaeifard, Mehdi Seif, Oksana Lastochkina dan Tao Li (2018), cahaya merupakan sumber utama energi untuk fotosintesis dan pertumbuhan. Perbedaan karakteristik cahaya seperti komposisi spektrum (panjang gelombang), intensitas, lama dan arah datang cahaya mempengaruhi pertumbuhan dan perkembangan tanaman.

Komposisi spektrum warna cahaya dapat dimanipulasi dengan cara penyaringan menggunakan bahan plastik sebagai penyaring (filter). Penguraian cahaya dari sumber polikromatik menjadi sumber monokromatik diusahakan dengan cara memfilter cahaya polikromatik. Pada beberapa penelitian sebelumnya telah 
dilakukan penyaringan cahaya matahari menggunakan sungkup plastik dan diperoleh hasil terdapat perbedaan hasil pertumbuhan tanaman akibat warna sungkup. Menurut Endang Sulistyaningsih, Budiastuti Kurniasih, Endang Kurniasih (2005), apabila cahaya tampak melalui suatu lembar plastik transparan maka radiasi yang diloloskan akan mempunyai warna yang sama seperti warna plastik. Jadi tanaman di bawah sungkup akan menerima radiasi sesuai dengan warna sungkup. Selanjutnya Intan Kartika Agnestika, Elis Nihayati dan Sitawati (2017) mengatakan, panjang gelombang cahaya berkorelasi dengan spektrum warna pada warna cahaya tampak, dimana masing masing warna memiliki interval panjang gelombang yang berbeda. Berdasarkan latar belakang di atas penelitian ini bertujuan : Mengetahui pengaruh warna sungkup untuk filter cahaya tampak terhadap pertumbuhan bibit anggrek semi hidroponik serta mengetahui warna plastik sungkup yang terbaik untuk pertumbuhan pada pembesaran bibit anggrek Dendrobium.

\section{METODE PENELITIAN}

\section{A Tempat dan Waktu}

Tempat yang digunakan untuk penelitian adalah : screen house di Fakultas Pertanian dan Laboratorium Fisika Fakuktas Keguruan dan Ilmu Pendidikan Universitas Siliwangi. Penelitian dilaksanakan selama 6 bulan dari bulan Mei 2019 sampai Agustus 2019, mulai dari persiapan hingga selesai.

\section{B Bahan dan Alat}

Bahan utama yang digunakan dalam penelitian ini adalah bibit anggrek Dendrobium hybrid Wira Pride asal botolan, bubuk batang pakis, fungisida, pupuk Gandasil D, vitamin B merk start
Linoux , cup plastik transparan, kantong platik kresek warna merah, jingga kuning hijau biru dan ungu dan putih (hdpe). Peralatan yang digunakan adalah Kit Optik, Spektrofotometer, Dualex 4 D Klorofil meter, mistar, camera HP, thermohigrometer, penggaris, timbangan elektrik hand sprayer, gelas ukur, pipet dll.

\section{Metode Penelitian}

Rancangan percobaan yang digunakan adalah Rancangan Acak Kelompok (RAK) dengan 4 kali pengulangan. Perlakuan yang dicoba yaitu 8 perlakuan yaitu : A: Pembanding/tanpa sungkup ; B: Warna sungkup merah ; C: Warna sungkup jingga; D: Warna sungkup Kuning ; E: Warna sungkup Hijau; F: Warna sungkup Biru ; G: Warna sungkup Putih ; $\mathrm{H}$ : Warna sungkup Ungu. Setiap perlakuan terdiri dari 5 bibit. Data dianalisis dengan menggunakan sidik ragam (Analysis of Variance), apabila terdapat pengaruh nyata dilanjutkan dengan Uji Berganda Duncans (DMRT ) pada taraf kepercayaan 95\%.

\section{Pelaksanaan Penelitian}

Bibit anggrek yang berasal dari botol hasil kultur jaringan diaklimatisasi selama 14 hari di komuniti pot (kompot). Setelah itu menyiapkan wadah tanam semi hidroponik berserta nutrisi hidroponiknya. Nutrisi semi hidroponik berupa larutan yang terdiri dari campuran Vitamin B (1\%), larutan pupuk daun Gandasil 0,5\% dan fungisda Antracol 0,5\%. Media tanam yang dipakai ialah cacahan pakis. Bibit yang sudah diaklimatisasi ditransplanting ke wadah tanam tadi, kemudian diberi penerapan perlakuan dengan cara disungkup

dengan berbagai warna plastik sesuai perlakuan. Unit percobaan tadi disusun di meja sesuai dengan tata letak percobaan di dalam rumah kasa 50\%. Pemeliharaan 
selama penelitian yaitu mempertahankan kelembaban rumah kasa, pemupukan dengan menyemprotkan pupuk daun pertumbuhan, penggantian larutan nutrisi sebulan satu kali dengan interval 10 hari satu kali, penyemprotan dengan fungisida 10 hari satu kali.

\section{E Parameter Penelitian}

Parameter pengamatan meliputi parameter penunjang meliputi :

a. Spektrum warna yang diloloskan oleh warna sungkup. Analisis spektrum warna pada cahaya tampak dengan menggunakan alat kit optic. Sampel dari sungkup yang berupa kantong plastik warna hdpe sesuai dengan perlakuan . Sampel tersebut difungsikan sebagai filter yang akan menyaring cahaya putih menjadi berkas cahaya monokrom. diambil dan modifikasi agar dapat diuji pada alat kit optik (Gambar 1)

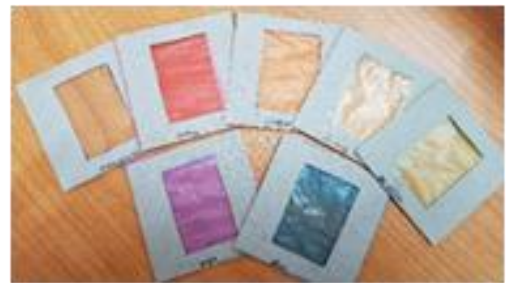

Gambar 1. Sampel wadah tanam pada pengujian filter cahaya

b. Gejala penyakit, diamati dengan cara visual terhadap keadaan helai daun, batang.

c. Serangan hama, diamati gejala serangan dan mencatat jenis hama yang menyerang.

d.Temperature, kelembaban, intensitas cahaya matahari, pengukuran dilakukan dengan alat termohigrometer dan lux meter, dan dilakuan pengamatan tiap hari

Parameter pengamatan utama meliputi :

a. Tinggi tanaman, diukur dengan mistar dengan ketelitian $1 \mathrm{~mm}$. Pengukuran tinggi tanaman dimulai dari pangkal batang sampai daun terpanjang, dilakukan pada umur 15, 30, 45 dan 60 hari setelah tanam (hst).

b. Jumlah daun, dihitung jumlah helaian daun yang sudah mekar sempurna, dilakukan pada umur yang sama dengan pengamatan tinggi tanaman.

c. Bobot segar per tanaman dengan cara menimbang seluruh bagian tanaman meliputi akar, batang dan daun pada umur

d. Jumlah akar per tanaman, dihitung semua akar yang tumbuh tanpa memperhatikan panjang pendeknya

e. Luas daun per tanaman diukur dengan menggunakan pendekatan software Image G.

f. Kandungan klorofil

Kandungan klorofil diukur dengan alat Dualex (Dx 4), klorofil, yang ditransformasikan. Transformasi merujuk pada a new optical leaf-clif meter for simultaneous non -destructive assessment of leaf chlorophyll and epidermal falanoids (Cerovic et al, 2012)

\section{HASIL DAN PEMBAHASAN}

\section{Spektrum Warna yang diloloskan oleh warna sungkup}

Karakteristik warna yang diloloskan hasil penyaringan cahaya putih polycrom oleh sungkup plastik warna tampak pada Gambar 2. 


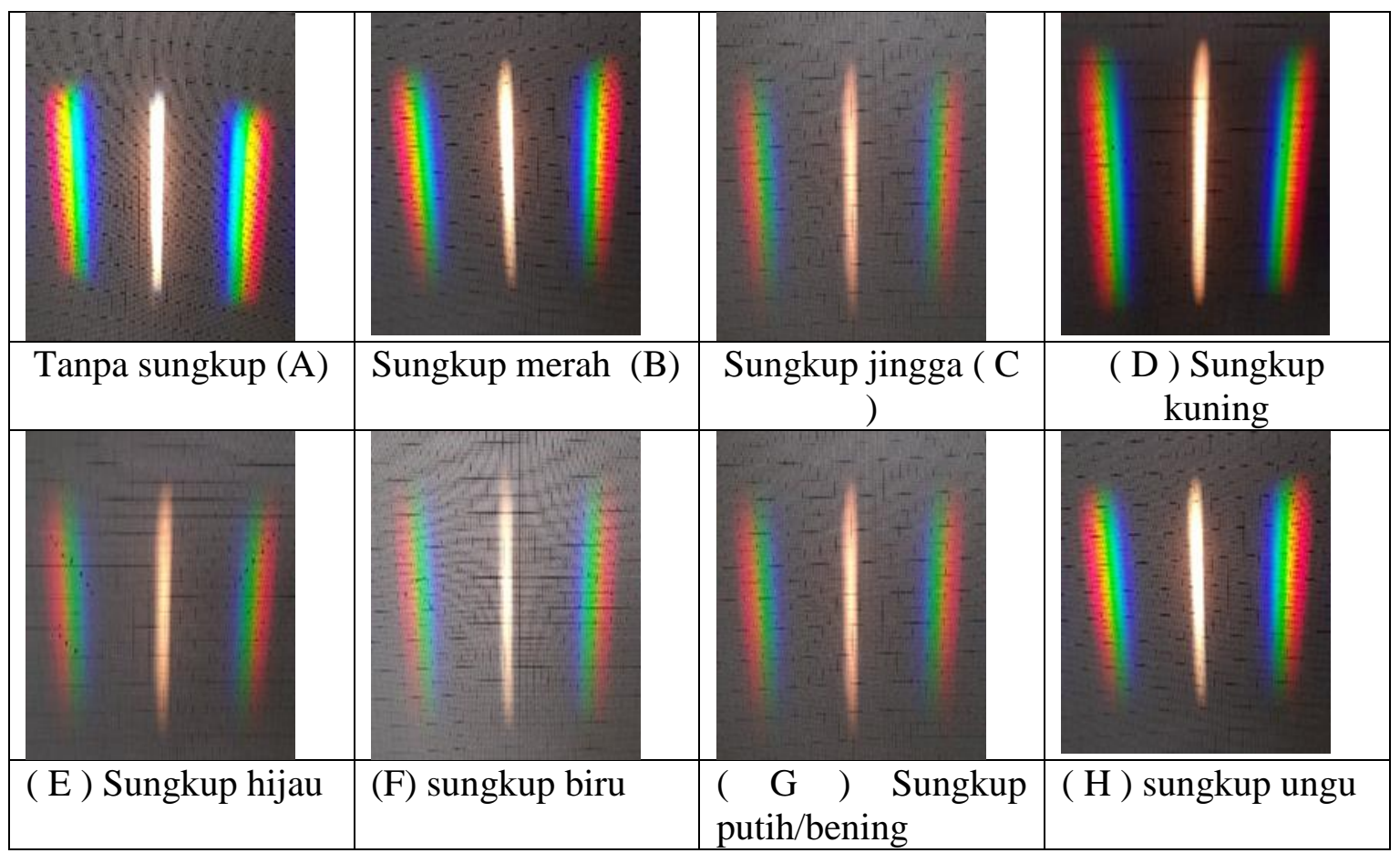

Gambar 2. Penyaringan cahaya dengan menggunakan sungkup plastik

Warna yang muncul tersebut menunjukkan panjang gelombang tertentu. (data disajikan pada Tabel 1).

Pada perlakuan tanpa sungkup (pembanding), warna yang muncul sebanyak 6 warna yang merupakan sperktrum warna cahaya tampak yang lengkap yaitu merah, jingga , kuning ,hijau, biru dan ungu dengan kisaran panjang gelombang $411 \mathrm{~nm}$ sampai dengan $676 \mathrm{~nm}$, jumlah panjang gelombang yang masuk sebanyak $3310 \mathrm{~nm}$. Sungkup yang berwarna bening warna muncul sama dengan tanpa sungkup yaitu sebanyak 6 warna, itu artinya sungkup warna bening masih meloloskan semua warna cahaya hanya dengan panjang gelombang yang sedikit berbeda yaitu $430 \mathrm{~nm}$ sampai dengan $652 \mathrm{~nm}$, dengan jumlah gelombang yang masuk $3318 \mathrm{~nm}$. Jumlah Sungkup yang berwarna ungu hanya mampu memfilter cahaya warna jingga dan kuning, karena masih bisa meloloskan warna merah hijau dan biru. Sungkup warna biru selain bisa meneruskan cahaya warna biru juga warna merah dan hijau. Sungkup warna hijau masih bisa meloloskan cahaya jingga dan ungu. Sungkup warna kuning tidak mampu memfilter semua warna cahaya, karena cahaya yang munculnya sama dengan pembanding dan sungkup warna bening yaitu sebanyak 6 warna (panjang gelombang $430 \mathrm{~nm}$ sampai dengan $652 \mathrm{~nm}$ ) dengan jumlah panjang gelombang $3318 \mathrm{~nm}$. Sungkup warna jingga seharusnya hanya bisa meloloskan cahaya warna jingga, tetapi cahaya warna merah, hijau dan biru juga masih lolos. Sungkup warna merah mampu memfilter 4 warna cahaya, namun demikian cahaya hijau masih lolos walaupun seharusnya yang lolos hanya warna merah saja. 
Tabel 1. Warna muncul dan panjang gelombang pada beberapa filter plastik

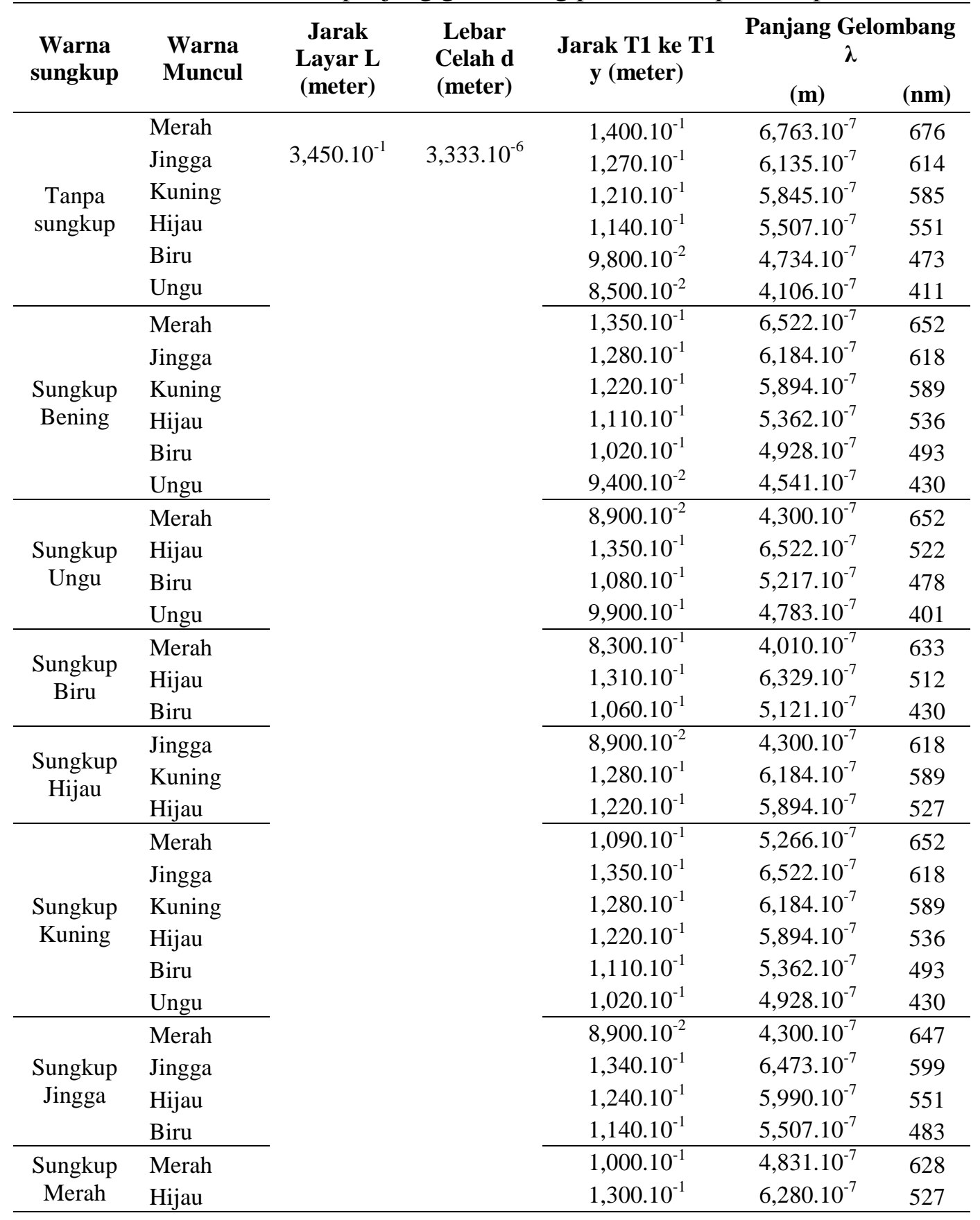

Temperatur penelitian dan kelembaban relatif ( $\mathrm{rH})$ di screen house selama percobaan selengkapnya disajikan pada lampiran 1. Lampiran tersebut mengungkapkan rata-rata suhu pagi $25^{\circ} \mathrm{C}$, siang $32^{\circ} \mathrm{C}$ dan sore $28{ }^{0} \mathrm{C}$, dengan kelembaban udara relatif pada waktu pagi hari sebesar $82 \%$, siang hari $64 \%$ dan sore hari $66 \%$. Kisaran rata-rata keseluruhan dari yang terendah $25,9^{\circ} \mathrm{C}$ sampai dengan 30,8 ${ }^{0} \mathrm{C}$ dengan kelembaban relatif sebesar $64 \%$ sampai dengan $78,3 \%$.

Keadaan lingkungan mikro terutama suhu pada screen house sedikit di atas suhu yang dipersyaratkan untuk pertumbuhan tanaman anggrek dan pembungaan. Menurut Yusnita (2010), suhu ideal untuk pertumbuhan dan pembungaan anggrek 
Dendrobium yaitu $25^{\circ} \mathrm{C}$ sampai $27^{0} \mathrm{C}$. Pertumbuhan anggrek Dendrobium akan terpacu jika dirawat pada kisaran suhu minimal $21^{\circ} \mathrm{C}$ sampai $23^{\circ} \mathrm{C}$ dan suhu maksimal $31^{\circ} \mathrm{C}$ sampai $34^{0} \mathrm{C}$ serta kelembaban relatife $60 \%$ sampai dengan $80 \%$.

\section{Pengamatan Utama}

Hasil analisis statistik terhadap parameter tinggi tanaman, jumlah daun, bobot basah per tanaman, luas daun dan kandungan klorofil dapat dilihat pada lampiran1 sampai dengan lampiran 12. Warna sungkup untuk memfilter cahaya tampak berpengaruh nyata hanya terhadap jumlah daun 30 hari setelah tanam, tetapi terhadap tinggi tanaman pada semua umur pengamatan, jumlah daun 15 , 45 dan 60 hst, bobot basah per tanaman, luas daun per tanaman dan kandungan klorofil daun berpengaruh tidak nyata.

\section{Tinggi Tanaman}

Bibit anggrek mengalami pertumbuhan tinggi tanaman dari pengamatan awal sampai akhir. Grafik pertumbuhan tinggi tanaman dari umur 15 hari setelah tanam sampai dengan 60 hari setelah tanam disajikan dengan grafik pada Gambar 3.

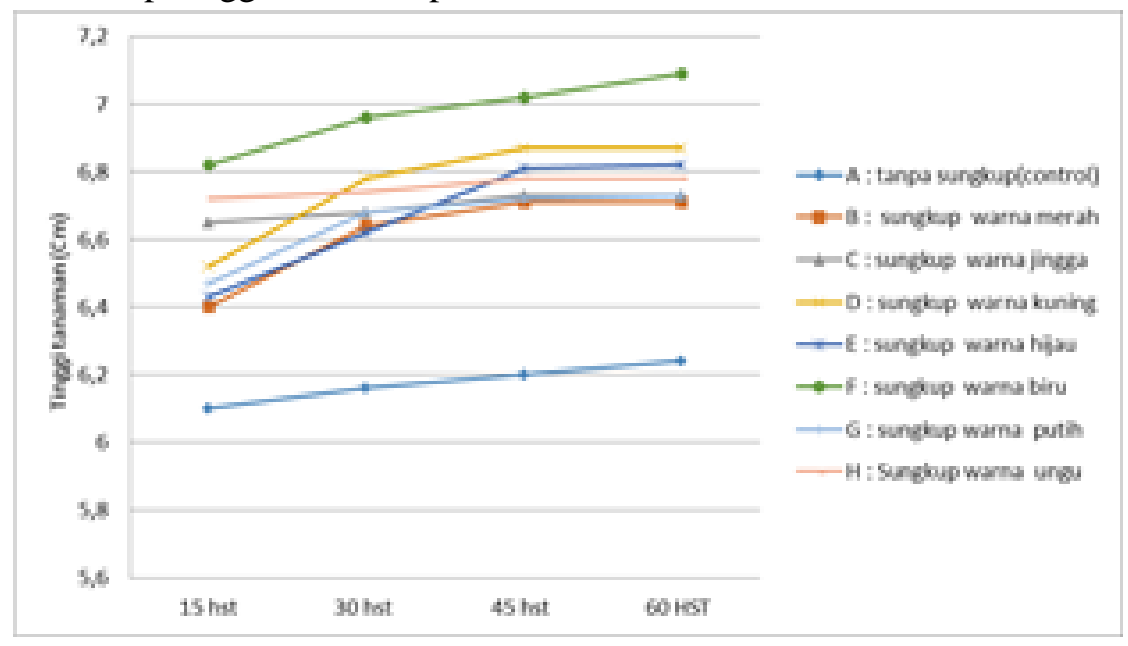

Gambar 3. Grafik pertumbuhan tinggi tanaman dari umur 15 hari setelah tanam sampai dengan 60 hari setelah tanam

Grafik di atas memperlihatkan pertumbuhan tinggi tanaman tanpa sungkup (sebagai pembanding) lebih rendah dibandingkan dengan pemakaian sungkup warna lainnya. Walaupun secara statistik tidak berbeda nyata. Pertumbuhan tinggi cenderung lebih cepat pada bibit anggrek yang diberi penyungkupan baik dengan warna bening maupun berwarna. Hal ini disebabkan pada bibit anggrek yang diberi penyungkupan laju reaksi evapotranspirasi tertahan karena kelembaban di dalam sungkup lebih tinggi. Kelembaban yang tinggi dan transpirasi rendah menyebabkan sel dalam keadaan turgor dan stomata akan terbuka sehingga fikasi $\mathrm{CO}_{2}$ lebih banyak diproses lebih lanjut melalui fotosintesis yang menghasilkan cadangan makanan yang diarahkan terhadap penambahan sel untuk meningkatkan tinggi tanaman.

Pertumbuhan tinggi tanaman dari umur 15 hari setelah tanam sampai umur 60 hari setelah tanam hanya mengalami penambahan yang berkisar dari $0,06 \mathrm{~cm}$ pada perlakuan sungkup plastik merah sampai dengan $0,39 \mathrm{~cm}$ pada filter hijau 
(Tabel 2). Menurut (Luttge,2001) dalam Nurunisa, Sasongko dan Indrianto (2018), anggrek memiliki karakteristik pertumbuhan yang lama, disebabkan oleh produktivitas fotosintesisnya yang rendah dibandingkan tanaman C 3.

Pengaruh warna sungkup untuk memfilter cahaya polikromatik menyebabkan tinggi tanaman berbeda tidak nyata pada semua umur pengamatan. Pengaruh warna sungkup terhadap tinggi tanaman pada umur 15, 30, 45 dan 60 hari setelah tanaman disajikan pada Tabel 2 .

Tabel 2. Pengaruh warna sungkup terhadap tinggi tanaman $(\mathrm{cm})$ umur 15, 30, 45 dan 60 hari setelah tanaman

\begin{tabular}{lcccc}
\hline \multicolumn{1}{c}{ Warna sungkup } & \multicolumn{4}{c}{ Umur (hst) } \\
& 15 & 30 & 45 & 60 \\
\hline A : tanpasungkup(control) & $6,10 \mathrm{a}$ & $6,16 \mathrm{a}$ & $6,20 \mathrm{a}$ & $6,24 \mathrm{a}$ \\
B: sungkup warna merah & $6,40 \mathrm{a}$ & $6,64 \mathrm{a}$ & $6,71 \mathrm{a}$ & $6,71 \mathrm{a}$ \\
C : sungkup warna jingga & $6,65 \mathrm{a}$ & $6,68 \mathrm{a}$ & $6,73 \mathrm{a}$ & $6,73 \mathrm{a}$ \\
D : sungkup warna kuning & $6,52 \mathrm{a}$ & $6,78 \mathrm{a}$ & $6,87 \mathrm{a}$ & $6,87 \mathrm{a}$ \\
E : sungkup warna hijau & $6,43 \mathrm{a}$ & $6,62 \mathrm{a}$ & $6,81 \mathrm{a}$ & $6,82 \mathrm{a}$ \\
F : sungkup warna biru & $6,82 \mathrm{a}$ & $6,96 \mathrm{a}$ & $7,02 \mathrm{a}$ & $7,09 \mathrm{a}$ \\
G : sungkup warna putih & $6,47 \mathrm{a}$ & $6,68 \mathrm{a}$ & $6,72 \mathrm{a}$ & $6,73 \mathrm{a}$ \\
H: sungkup warna ungu & $6,72 \mathrm{a}$ & $6,74 \mathrm{a}$ & $6,78 \mathrm{a}$ & $6,78 \mathrm{a}$ \\
\hline
\end{tabular}

Keterangan: angka yang diikuti oleh huruf kecil yang sama tidak berbeda nyata menurut uji jarak berganda Duncan pada taraf nyata $5 \%$

Tinggi tanaman pada perlakuan tanpa sungkup, warna sungkup bening dan warna sungkup lainnya (biru, hijau, kuning jingga dan merah) menunjukkan tidak berbeda nyata pada semua umur pengamatan. Hal ini disebabkan sungkup yang ditujukan untuk menyaring cahaya polikromatik menjadi monokromatik terbuat dari plastik hdpe (high density polyethilen) walaupun berwarna tetapi transparan, sehingga masih ditembus oleh cahaya dengan warna lain selain warna sungkup itu. Warna plastik hdpe pada umumnya bening transparan, berwarna merah, kuning hijau biru dan warna lainnya (Pancabudi HDPE (2019).

Warna cahaya yang lolos ke dalam sungkup dan sampai ke permukaan bibit anggrek bukan lagi warna spesifik dalam rentang yang sempit tetapi beberapa warna yang memiliki beberapa rentang panjang gelombang. panjang gelombang dengan rentang yang panjang. Panjang gelombang dari sumber cahaya dapat dikaitkan dengan besar energi yang dibawa. Pada panjang gelombang dengan rentang yang panjang ini akan menghasilkan energi dengan rentang panjang pula. Berbagai perlakuan sungkup tadi tidak mampu memfilter menjadi panjang gelombang yang spesifik, sehingga energi yang diterima oleh bibit anggrek sama besarnya dengan bibit anggrek pada perlakuan tanpa sungkup (kontrol), oleh karena itu hasil fotosintesis yang diarahkan untuk bahan pembentukan tinggi tanaman juga tidak berbeda, akibatnya pertumbuhan tinggi tanaman berbeda tidak nyata.

Selain itu juga disebabkan sungkup plastik hdpe yang transparan menyebabkan cahaya bisa datang ke segala arah dengan merata. Cahaya matahari yang masuk berpengaruh terhadap pembentukan hormon auksin. Hormon auksin terdistribusi merata sehingga pada bibit yang tumbuh di bawah sungkup tinggi tanamannya akan normal sama dengan bibit pada perlakuan tanpa diberi sungkup. 


\section{Jumlah Daun}

Pengaruh warna sungkup untuk memfilter cahaya terhadap jumlah daun tampilkan pada Tabel 3 .

Jumlah daun umur 15 hst tidak berbeda nyata karena pengaruh warna sungkup. Sampai dengan umur 15 hst panjang gelombang yang diterima bibit dari rentang yang tidak terlalu sempit sampai rentang yang panjang belum mampu untuk mendorong inisisasi pembentukan helai daun. Energi yang dihasilkan oleh panjang gelombang sesuai dengan warna cahaya yang sampai ke permukaan bibit untuk proses fotosintesis belum cukup menyediakan fotosintat untuk pembentukan helai daun. Selain itu cahaya yang masuk masih terdistribusi merata ke semua permukaan bibit walau dihalangi oleh sungkup sama meratanya dengan pada perlakuan tanpa sungkup. Cahaya yang merata ini akan mendorong kerja hormon untuk menginisiasi jumlah daun. Hormon sitokinin berfungsi diantaranya untuk pembentukan daun.

Pada umur 30 hst, perlakuan warna sungkup menyebabkan perbedaan yang nyata terhadap jumlah daun. Jumlah daun pada perlakuan kontrol (3,33 helai) merupakan jumlah daun yang terendah berbeda nyata dengan perlakuan lainnya. Hal ini disebabkan pada perlakuan tanpa sungkup, walaupun cahaya tampak yang sampai pada permukaan tanaman lengkap semua, tetapi memiliki kelembaban yang lebih rendah di sekitar iklim mikro tanaman, akibatnya pembentukan daun terhambat. Perlakuan sungkup warna kuning berbeda tidak nyata dengan sungkup warna putih. Jumlah daun lebih banyak pada sungkup kuning (5,42 helai) yang tidak berbeda nyata dengan warna putih $(5,00$ helai).

Tabel 3. Pengaruh warna sungkup terhadap jumlah daun (helai) umur 15, 30, 45, dan 60 hari setelah tanaman

\begin{tabular}{lcccc}
\hline Warna sungkup & \multicolumn{4}{c}{ Umur (hst) } \\
& 15 & 30 & 45 & 60 \\
\hline A : tanpavsungkup(control) & $4,08 \mathrm{a}$ & $3,33 \mathrm{a}$ & $2,50 \mathrm{a}$ & $2,33 \mathrm{a}$ \\
B : sungkup warna merah & $4,67 \mathrm{a}$ & $4,58 \mathrm{c}$ & $3,50 \mathrm{a}$ & $3,00 \mathrm{a}$ \\
C : sungkup warna jingga & $4,50 \mathrm{a}$ & $4,83 \mathrm{c}$ & $3,50 \mathrm{a}$ & $3,00 \mathrm{a}$ \\
D : sungkup warna kuning & $5,33 \mathrm{a}$ & $5,42 \mathrm{~d}$ & $4,00 \mathrm{a}$ & $3,08 \mathrm{a}$ \\
E : sungkup warna hijau & $3,92 \mathrm{a}$ & $3,92 \mathrm{~b}$ & $3,42 \mathrm{a}$ & $2,92 \mathrm{a}$ \\
F : sungkup warna biru & $4,42 \mathrm{a}$ & $3,75 \mathrm{ab}$ & $3,17 \mathrm{a}$ & $2,67 \mathrm{a}$ \\
G : sungkup warna putih & $4,92 \mathrm{a}$ & $5,00 \mathrm{~cd}$ & $3,75 \mathrm{a}$ & $3,50 \mathrm{a}$ \\
H : Sungkup warna ungu & $4,25 \mathrm{a}$ & $4,00 \mathrm{~b}$ & $3,00 \mathrm{a}$ & $3,33 \mathrm{a}$ \\
\hline
\end{tabular}

Keterangan: angka yang diikuti oleh huruf kecil yang sama tidak berbeda nyata menurut uji jarak berganda Duncan pada taraf nyata 5

Pengaruh warna sungkup terhadap jumlah daun dapat dilihat pada gambar 4. Sungkup warna kuning dan sungkup warna putih dapat meloloskan semua warna cahaya tampak yaitu warna merah, jingga, kuning, hijau, biru dan ungu seperti telah diterangkan pada pengamatan penunjang. Pada rentang panjang gelombang yang tidak spesifik tersebut dapat memicu energy ATP yang dibutuhkan untuk mendorong pembelahan sel, agar terjadi inisisasi daun dan tunas/ bulb anggrek yang sudah memiliki daun. Energi yang ditangkap ditransfer antara molekul fotosistem sampai mencapai molekul klorofil pada pusat reaksi. Menurut Sri Haryanti (2008), untuk terjadinya fotosintesis, energi dalam bentuk elektron yang tereksitasi pada berbagai 
pigmen harus disalurkan ke pigmen pengumpul energi yang disebut pusat reaksi.

Jumlah daun pada umur 45 hst dan 60 hst, berbeda tidak nyata karena pada tersebut ada beberapa daun helaian yang letaknya paling bawah mengalami rontok karena busuk. Hal ini disebabkan media tanam yang berasal dari cacahan pakis yang terlalu lembab. Media tanam pakis mampu menyerap cairan yang berasal dari cairan semi hidroponik, ditambah lagi tingkat evapotranspirasi yang rendah menyebabkan daun yang paling banyak lepas dari batangnya (rontok).

Pada rentang panjang gelombang yang tidak spesifik tersebut dapat memicu energy ATP yang dibutuhkan untuk mendorong pembelahan sel, agar terjadi inisisasi daun dan tunas/ bulb anggrek yang sudah memiliki daun. Energi yang ditangkap ditransfer antara molekul fotosistem sampai mencapai molekul klorofil pada pusat reaksi. Menurut Sri Haryanti (2008), untuk terjadinya fotosintesis, energi dalam bentuk elektron yang tereksitasi pada berbagai pigmen harus disalurkan ke pigmen pengumpul energi yang disebut pusat reaksi.

Jumlah daun pada umur 45 hst dan 60 hst, berbeda tidak nyata karena pada tersebut ada beberapa daun helaian yang letaknya paling bawah mengalami rontok karena busuk. Hal ini disebabkan media tanam yang berasal dari cacahan pakis yang terlalu lembab. Media tanam pakis mampu menyerap cairan yang berasal dari cairan semi hidroponik, ditambah lagi tingkat evapotranspirasi yang rendah menyebabkan daun yang paling banyak lepas dari batangnya (rontok).

Pengaruh warna sungkup terhadap parameter bobot basah, luas daun, jumlah akar dan kandungan klorofil disajikan pada Tabel 4.

Tabel 4. Pengaruh warna sungkup terhadap, bobot basah, luas daun,jumlah akar dan kandungan klorofil.

\begin{tabular}{lcccc}
\hline \multicolumn{1}{c}{ Warna sungkup } & $\begin{array}{c}\text { Bobot } \\
\text { basah per } \\
\text { tanaman }\end{array}$ & $\begin{array}{c}\text { Luas daun } \\
\text { Per } \\
\text { tanaman }\end{array}$ & Jumlah akar & $\begin{array}{c}\text { Kandungan } \\
\text { klorofil }\end{array}$ \\
\cline { 2 - 5 }$(\mathrm{g})$ & $\mathrm{cm}^{2}$ & (helai) & $(\mathrm{g} / \mathrm{cm} \mathrm{2})$ \\
\hline A : tanpa sungkup(control) & $0,6 \mathrm{a}$ & $5,34 \mathrm{a}$ & $5,50 \mathrm{a}$ & $17,18 \mathrm{a}$ \\
B : sungkup warna merah & $1,1 \mathrm{a}$ & $7,21 \mathrm{a}$ & $5,67 \mathrm{a}$ & $12,26 \mathrm{a}$ \\
C : sungkup warna jingga & $1,2 \mathrm{a}$ & $3,99 \mathrm{a}$ & $8,25 \mathrm{a}$ & $15,82 \mathrm{a}$ \\
D : sungkup warna kuning & $1,3 \mathrm{a}$ & $4,50 \mathrm{a}$ & $7,33 \mathrm{a}$ & $16,38 \mathrm{a}$ \\
E : sungkup warna hijau & $0,9 \mathrm{a}$ & $5,54 \mathrm{a}$ & $5,75 \mathrm{a}$ & $9,99 \mathrm{a}$ \\
F : sungkup warna biru & $0,9 \mathrm{a}$ & $5,77 \mathrm{a}$ & $7,42 \mathrm{a}$ & $14,58 \mathrm{a}$ \\
G : sungkup warna putih & $1,4 \mathrm{a}$ & $8,12 \mathrm{a}$ & $7,75 \mathrm{a}$ & $13,03 \mathrm{a}$ \\
H : Sungkup warna ungu & $0,9 \mathrm{a}$ & $7,10 \mathrm{a}$ & $5,50 \mathrm{a}$ & $13,03 \mathrm{a}$ \\
\hline
\end{tabular}

Keterangan: angka yang diikuti oleh huruf kecil yang sama tidak berbeda nyata menurut uji jarak berganda Duncan pada taraf nyata 5

Tabel 4 mengungkapkan perlakuan warna sungkup menyebabkan tidak berbeda nyata terhadap bobot basah, luas daun, jumlah akar dan kandungan klorofil.

Bobot basah pertanaman pada perlakuan tanpa sungkup dan perlakuan warna sungkup lainnya tidak berbeda nyata, meskipun secara umum, nilai rata-rata pada perlakuan tanpa sungkup menyebabkan bobot basah terendah. Hal tersebut disebabkan pada perlakuan dengan sungkup berbagai warna, kelembaban relatif iklim mikro sekitar bibit 
selalu terjaga. Tanaman akan menyerap uap air tersebut dan menyebabkan bobot basah meningkat. Bobot basah pada perlakuan berbagai warna sungkup tidak berbeda nyata. Hal ini disebabkan perlakuan warna sungkup ditempatkan pada naungan dengan intensitas cahaya matahari yang sama (40 $\%)$. Intensitas cahaya matahari di dalam ruangan screen house rata- rata berkisar pada pagi hari : 948, 47 lux, siang hari : 2867, 40 lux dan sore 472,77 lux. Intensitas cahaya yang sama akan menyebabkan jumlah energi cahaya per satuan luas dan per satuan waktu yang diterima tanaman sama. Pada intensitas cahaya yang rendah mempengaruhi terbentuknya metabolit primer yang terbatas jumlahnya.

Luas daun pertanaman pada semua warna sungkup tidak berbeda nyata . Hal ini disebabkan oleh supply metabolit primer hasil fotosintesis untuk bahan luas daun sangat terbatas karena intensitas cahaya yang rendah.

Jumlah akar pada berbagai warna sungkup tidak berbeda nyata. Hal ini disebabkan selain kurangnya metabolit yang dialirkan untuk pembentukan bahan akar, juga dipengaruhi oleh media tanamnya yaitu serpihan batang pakis. Struktur pakis yang berongga memiliki oksigen, sehingga akar tanaman berkembang baik pada semua perlakuan.

Kandungan klorofil juga tidak dipengaruhi oleh warna sungkup. Hal ini disebabkan semua tanaman mendapatkan perlakuan intensitas cahaya yang sama. Pada kondisi yang ternaungi, umumnya klorofil lebih banyak karena untuk memaksimalkan penyerapan cahaya pada kondisi intensitas cahaya rendah.

Menurut Salisburi dan Ross, (1995), berdasarkan bobot, daun pada kondisi ternaungi umumnya mempunyai klorofil yang lebih banyak. Menurut Lakitan (1993) Intensitas cahaya matahari merupakan sumber energy utama untuk melakukan proses fotosintesis (Lakitan , 1993). Hasil fotosintesis akan ditraslokasikan keseluruh jaringan tanaman melalui floem, yang selanjutnya energy hasil fotosintesis tersebut akan dipergunakan tanaman untuk pertumbuhan tunas, daun dan batang sehingga tanaman tumbuh optimal

Penyebab utama yang mungkin adalah bahwa intensitas cahaya yang rendah mengurangi suplai karbohidrat ke apeks, padahal karbohidrat, terutama sukrosa, memegang peranan penting dalam transisi juvenil ke dewasa. Sel palisade daun yang ternaungi lebih pendek daripada daun yang terkena cahaya penuh dan konsentrasi rubisco lebih sedikit (Taiz and Zeiger 2002).

\section{KESIMPULAN}

Berdasarkan penelitian yang telah dilakukan dapat disimpulkan :

1. Warna sungkup belum sepenuhnya efektif menyaring cahaya tampak sehingga tidak mempengaruhi terhadap tinggi tanaman bibit anggrek dendrobium pada teknik semi hidroponik

2. Warna sungkup kuning dan putih dapat meningkatkan jumlah daun bibit anggrek dendrobium hanya pada umur 30 hari setelah tanam.

\section{SARAN}

1. Perlu dilakukan penelitian lebih lanjut, tentang pengaruh warna sungkup untuk menyaring cahaya cahaya tampak terhadap pertumbuhan anggrek Dendrobium pada semi hidroponik dengan media tanam yang tidak terlalu menyimpan kelembaban misalnya dengan media tanam sabut kelapa.

2. Perlu dilakukan penelitian lebih lanjut tentang pengaruh warna sungkup dari lembaran Low Density Polietilen yang dipakai dinding ruang tanam (chamber sederhana) untuk melihat pengaruhnya 
terhadap pertumbuhan bibit anggrek Dendrobium

\section{DAFTAR PUSTAKA}

Astried Naomi, Jeni Pertiwi, Putri Ayu Permatasari, Shabrina Nur Dini dan Asep Saefullah, 2018, Keefektifan Spektrum Cahaya terhadap pertumbuhan Tanaman Kacang Hijau (Vigna radiata), http//jurnal.untirta.ac.id/ index.php/gravity, ISSN 2442-515x,

Permatasai, ISSN2528-1976 (Diakses 8 Februari, 2019)

Boga, A.K., Williem, Alfa Tumbuan, 2015, Potensi pengembangan agribisnis bunga anggrek di kota Jawa Timur, Jurnal LPPM Bidang EKOSOSDUDKUM. 12:19-20.

Cahyo, P.H., 2009, Teknik Kultur Jaringan Anggrek Dendrobium $s p$ di Pembudidayaan Anggrek Widorokandang Yogyakarta, Tugas Akhir, Universitas Sebelas Maret Surakarta.

Endang Sulistyaningsih, Budiastuti Kurniasi dan Endah Kurniasih, 2005, Pertumbuhan dan Hasil Caisin Pada berbagai Warna Sungkup Plastik, Ilmu Pertanian Vol 12 No 1, 2005.

Erviani, L. 2012, Gelombang Cahaya, Erlangga, Jakarta:XII, 278 halaman.

I Gede Ketut Adiputra, 2009, Aklimatisasi Bibit Anggrek Pada Awal Pertumbuhannya Di Luar Kultur Jaringan, Jurusan Biologi, FMIPA, Universitas Hindu Indonesia, Denpasar http://www.slemankab.go.id. Pemerintah Kabupaten Sleman Ketinggian Tempat, Iprofil-kabupatensleman/geografi/ (diakses 10 Februari, 2019)

Hayati, N.Q., 2013, Pengembangan Varietas Baru Anggrek Dendrobium Bunga Potong Dengan Pendekatan Quality Function Deployment (QFD), Tesis, Institut Pertanian Bogor.

Intan Kartika Agnestika, Elis Nihayati dan Sitawati, 2017, Simulasi Panjang gelombang Cahaya terhadap Kualitas Tanaman Krisan (Chrysanthemum morifolium) Potong, Jurnal Produksi Tanaman Vol 5 No 7, Juli 2017 : 1187-1195 ISSn 2527-8452 (Diakses 12 Februari 2018).

Kit T.I., 2005, Anggrek Dendrobium, PT Trubus Swadaya, Depok.

Pranata, 2010, Anggrek Dendrobium, http://digilib.unila.ac.id./, (Diakses 15 Januari 2019).

Pratignja Sunu dan Wartoyo, 2016, Buku Ajar Dasar Hortikultura, Jurusan Agronomi Fakultas pertanian Sebelas Maret Surakarta, hal 17.

Lakitan, B. 1993, Fisiologi Pertumbuhan dan Perkembangan Tanaman. PT. Raja Grafindo Persada, Jakarta

Salisbury, F.B. and C.W. Ross. 1995. Fisiologi Tumbuhan, Jilid 3, Bandung: Penerbit ITB

Taiz L.,E.Zeiger, 2003, Plant Physiology. The Benyamin/Cumming Publishing Company, Inc New York, 